\title{
Integrating a reproductive health framework within primary care services: The experience of the Reproductive Health Intervention Study
}

Karima Khalil

Abdel Moneim Farag

Assem Anwar

Dina Galal

Olfia Kamal

See next page for additional authors

Follow this and additional works at: https://knowledgecommons.popcouncil.org/departments_sbsr-rh

Part of the International Public Health Commons, Maternal and Child Health Commons, and the Women's Health Commons

How does access to this work benefit you? Let us know!

\section{Recommended Citation}

Khalil, Karima, Abdel Moneim Farag, Assem Anwar, Dina Galal, Olfia Kamal, Karraze Shorbagi, Miral Breebaart, Hind Khattab, Nabil Younis, and Huda Zurayk. 2000. "Integrating a reproductive health framework within primary care services: The experience of the Reproductive Health Intervention Study," Policy Series in Reproductive Health. Cairo: Population Council. 


\section{Authors}

Karima Khalil, Abdel Moneim Farag, Assem Anwar, Dina Galal, Olfia Kamal, Karraze Shorbagi, Miral Breebaart, Hind Khattab, Nabil Younis, and Huda Zurayk 


\title{
INTEGRATING A REPRODUCTIVE HEALTH FRAMEWORK WITHIN PRIMARY CARE SERVICES
}

\author{
The Experience of the Reproductive Health Intervention Study
}

\section{THE POLICY SERIES IN REPRODUCTIVE HEALTH}

$\begin{array}{cc} & \text { No. } 6 \\ \text { Karima Khalil, M.P.H. } \\ \text { Public Health } & \begin{array}{c}\text { Abdel Moneim Farag, M.D. } \\ \text { Gynecology \& Obstetrics }\end{array} \\ \text { Assem Anwar, M.D. } & \text { Dina Galal, M.P.H. } \\ \text { Gynecology \& Obstetrics } & \text { Public Health } \\ \text { Olfia Kamal, M.A. } & \text { Nadine Karraze Shorbagi, M.A. } \\ \text { Economics, Political Science } & \text { Medical Anthropology } \\ \text { Miral Breebaart, B.Sc. } & \text { Hind Khattab, Ph.D. } \\ \text { Computer Science } & \text { Anthropology } \\ \text { Nabil Younis, M.D. } & \text { Huda Zurayk, Ph.D. } \\ \text { Gynecology \& Obstetrics } & \text { Biostatistics }\end{array}$

REPRODUCTIVE HEALTH WORKING GROUP HOUSED AT

THE POPULATION COUNCIL REGIONAL OFFICE WEST ASIA AND NORTH AFRICA 
The Population Council seeks to improve the well-being and reproductive health of current and future generations around the world and to help achieve a humane, equitable, and sustainable balance between people and resources.

The Council, a nonprofit, nongovernmental research organization established in1952, has a multinational Board of Trustees; its New York headquarters supports a global network of regional and country offices.

The Policy Series in Reproductive Heath is produced by the Reproductive Health Working Group housed in the Population Council Regional Office for West Asia and North Africa, P.O. Box 115, Dokki, Giza, Egypt.

(C) Copyright 2000

The Population Council 


\section{TABLE OF CONTENTS}

Preface: The Policy Series in Reproductive Health IV

Reproductive health Intervention Study Team Members V

Acknowledgements VI

Abstract

What does adopting this approach mean for primary care services?

The Reproductive Health Intervention Study

The background to the work: What do we really know about women's reproductive health?

What are the framework's main components?

Where the work took place:

How the team developed the framework:

The benefits of multidisciplinarity:

The benefits of the MOHP's input:

The framework that was developed:

A. The Supply side

1. Component One: Expanding Reproductive Health Services

2. Component Two: Provider Training - The main principles

3. Component Three: Upgrading the physical infrastructure and providing equipment

B. The Demand side: Health Education and Awareness-Raising Are women aware of reproductive health conditions?

What the health education program aimed to do:

Monitoring and Evaluation:

Monitoring tools:

How was the monitoring done?

What the monitoring exercise showed:

Evaluation: Feasibility and not impact

Positive changes:

What did we learn?

Challenges

Policy Implications

Looking Ahead: The Next Step

REFERENCES

APPENDIX I: The Medical Record 


\section{Preface}

\section{THE POLICY SERIES IN REPRODUCTIVE HEALTH}

Papers in the Policy Series in Reproductive Health aim at sharing research undertaken by members of the Reproductive Health Working Group with policy makers, program managers and health advocates in the region, the developing world and the international community. The Reproductive Health Working Group (RHWG) was established in 1988 as part of a Special Program on the health of women and children within the context of the family and community initiated by the Population Council's Regional Office for West Asia and North Africa (WANA) region. The Working Group includes professionals with specialization in anthropology, biostatistics, demography, medicine, public health and sociology, residing in various countries of the region.

The Working Group delineated three key issues which were considered as central to women's reproductive health in the WANA region: first, women's physical health in terms of morbidity conditions related to the reproductive function; second, women's perceptions of their health and their dignity in relation to reproduction; and third, on the health service side, the quality of reproductive health services directed at women. The Working Group has been undertaking studies addressing these issues in countries of the region since 1989. Further research interests are currently emerging concerned with developing an intervention framework to improve reproductive health within primary care settings, and with investigating physicians' perceptions of women's health.

The Policy Series in Reproductive Health and Monographs in Reproductive Health are two complementary publications issued by the Reproductive Health Working Group. Monographs in Reproductive Health present original research, reviews of literature and theoretical discussions. They address researchers and students primarily and aim to contribute to advancement of interdisciplinary approaches in research on reproductive health. Papers in the Policy Series in Reproductive Health reach out with frameworks, methodologies and evidence of research to policy makers, program managers and health advocates, bringing out interdisciplinary perspectives. In this way they aim to contribute to the development of more holistic approaches that can better meet the health needs of women in the developing world. 


\title{
Reproductive Health Intervention Study Team Members
}

\section{Delta Consultants}

Dr. Hind Khattab

Ms. Olfia Kamal

Ms. Nadine Karraze Shorbagi

Dr. Dina Galal

\author{
Al-Azhar University \\ Dr. Nabil Younis \\ Dr. Abdel Moneim Farag \\ Dr. Assem Anwar
}

The Population Council

Dr. Karima Khalil

Ms. Miral Breebaart

Faculty of Health Sciences - American University in Beirut

Dr. Huda Zurayk 


\section{Acknowledgements}

The authors wish to acknowledge the valuable participation of the field researchers at Delta Consultants as part of the implementing team that conducted the study. Thanks are due to Dr. Mervat el Geneidy as well as to the nurse trainers Nemat Aboul Seoud, Boshra Rabab and Sophie Farag. Thanks are also due to Faten Mohamed who trained the lab technicians. The authors are also grateful to the members of the Reproductive Health Working Group for their feedback during various stages of the study's progress. Dr. Salah Mawajdeh's contribution to the design of the medical records was very valuable.

The authors acknowledge with gratitude the invaluable comments made by Dr. Cynthia Myntti on the manuscript of this paper. They similarly wish thank Dr. Barbara Ibrahim for her editorial contribution and Noha Gaballah and Miral Breebaart for their help in preparing it for publication.

The authors would also like to express their appreciation to Ministry of Health and Population personnel at the central levels in Cairo and Giza and the district level in Ossim for their support. Dr. Emad Ezzat's assistance in assessing the framework's cost is much appreciated. We would like to particularly thank the primary care providers who collaborated so enthusiastically on the framework's implementation.

The Reproductive Health Intervention Study was supported by the United Nations Fund for population Activities (UNFPA), the Population Council and the Ford and Rockefeller Foundations. The study was a collaborative effort with the Egyptian Ministry of Health and Population. Publication of this paper is supported by the Ford Foundation grant to the Reproductive Health Working Group. 


\begin{abstract}
This paper describes the experience of the Reproductive Health Intervention Study. The study involved the design and testing of a model of essential reproductive health services. It identified a framework of basic service components that address reproductive health, and showed that their delivery is possible at the primary level. The aim of this paper is to give an overview of this experience, which illustrates how the reproductive health approach can be translated into actual service delivery at the primary care level, in a developing country setting. The paper outlines the framework which was developed and tested by the team in three rural primary care clinics in Giza, Egypt and which is a concrete example of "implementing Cairo" on the ground. The paper presents the main achievements as well as challenges and discusses the most salient policy implications.
\end{abstract}



Reproductive health is a relatively new approach. It seeks to address women's health holistically and includes, but is not limited to, family planning and maternal issues. Of the various definitions of health currently in use, there is general agreement that it includes "a state of complete physical, mental and social well-being and not merely the absence of disease or infirmity"1. In this context, reproductive health is not limited to the absence of disease or a disorder of the reproductive process. It means that people should have the ability to live through their reproductive years and beyond with reproductive choice, dignity, with successful childbearing, and to be free of reproductive disease and risk. ${ }^{2}$

This approach has gained wide acceptance since $\mathrm{ICPD}^{3}$, the forum held in Cairo where reproductive health was first championed in 1994. On ICPD's fifth anniversary the UN undertook a global review of what had been accomplished in implementing its agenda. The year-long series of meetings, known as ICPD +5 , showed that while significant progress has been made, considerable barriers remain to fully implementing the ICPD's progressive program of action. 4

\section{What does adopting this approach mean for primary care services?}

This approach is new and challenging in many ways. Adopting it means that existing services have to change what services they provide and how they provide them. It means that the focus must shift from contraceptive targets and from seeing women mainly as mothers. Because primary care is limited to the essentials in what it can provide, it becomes necessary to be selective when planning to integrate reproductive health services within such services. The question becomes "What should essential reproductive health services consist of?"

The Reproductive Health Intervention Study described in this paper has tried to answer this question. It designed and tested a model of services that can be adapted for wider application in Egypt and elsewhere. The study identified a framework of essential service components that address reproductive health, and showed that their delivery is possible at the primary level. The aim of this paper is to give an overview of this experience, which illustrates how the reproductive health approach can be translated into actual service delivery at the primary care level, in a developing country setting. It outlines the framework which was developed and tested by the team in three rural primary care clinics in Giza, Egypt and which is a concrete example of "implementing Cairo" on the ground.

\footnotetext{
${ }^{1}$ WHO Constitution

${ }^{2}$ Fathalla (1991).

${ }^{3}$ The International Conference on Population and Development, held in Cairo in 1994.

${ }^{4}$ For a review of the progress and challenges, see Catino, J. (1999).
} 


\section{The Reproductive Health Intervention Study}

This study was carried out by a subgroup of the Reproductive Health Working Group ${ }^{5}$ (RHWG), which came together with other researchers to form the Reproductive Health Intervention Study Team. The team was made up of an anthropologist, a field research manager, a public health physician and a health education specialist (based at Delta Consultants), three obstetrician-gynecologists (based at Al Azhar University Faculty of Medicine), a bio-statistician demographer, a public health physician and a research assistant (based at the Population Council). The study was conceptualized, designed and implemented by the team. The team members raised the funds to do the study, carried out the baseline analysis, implemented the framework's various components and evaluated the performance of its various components.

The study has been a collaborative effort with the Egyptian Ministry of Health and Population and has received support from the United Nations Fund for Population Activities (UNFPA), the Population Council and the Ford and Rockefeller Foundations. The framework's various components are individually described in detail in separate working papers and manuals.

\section{The background to the work: What do we really know about women's reproductive health?}

The team's interest in developing a framework of essential reproductive health services grew out of prior community-based work that it had done, also in rural Giza. That research, which came to be known informally as the Giza study, showed that women had an unexpectedly high level of gynecological and related illnesses ${ }^{6}$, (see Table 1). This was echoed by several other studies ${ }^{7}$ in other parts of the world. In fact, conditions like reproductive tract infections have been found to be very common in almost all of the developing countries in which they have been investigated. ${ }^{8}$ Findings like these led the team to examine the gap that exists between this burden of disease and the services that are provided for women in primary

\footnotetext{
5 The RHWG was established in 1987 and is a regional multidisciplinary group of researchers based in the Arab world and Turkey, who share an interest in reproductive health. Their research interests include the prevalence of reproductive morbidities in various settings, health awareness and health-seeking behaviors, women's perceptions of health and illness and the processes which shape physician's perceptions of women's reproductive health, among others.

${ }^{6}$ Younis, et al. (1993).

${ }^{7}$ Wasserheit (1989), Chowdhury et al. (1995), Hussain et al. (1996).

${ }^{8}$ Wasserheit (1989), M.E. Khan (1998).
} 
care. The team's interest coincided with the global concern ${ }^{9}$ which grew around ICPD, to identify how primary services can be best developed to reflect the reproductive health approach.

Table 1 Percent Prevalence of Main Morbidity Conditions found, from Younis et al.

\begin{tabular}{|c|c|}
\hline Condition & $\%$ \\
\hline Reproductive Tract Infections ${ }^{\mathrm{a}, \mathrm{b}}$ & 51 \\
\hline Vaginitis $^{\mathrm{a}}$ & 44 \\
\hline Bacterial Vaginosis & 22 \\
\hline Trichomonas & 18 \\
\hline Candida & 11 \\
\hline Cervicitis $^{\mathrm{b}}$ & 10 \\
\hline Pelvic Inflammatory Disease ${ }^{\mathrm{b}}$ & 2 \\
\hline Cervical Ectopy $^{\mathrm{b}}$ & 22 \\
\hline Suspicious Cervical Cell Changes ${ }^{\mathrm{a}}$ & 11 \\
\hline Genital Prolapse $^{b}$ & 56 \\
\hline Posterior or Anterior Vaginal & 27 \\
\hline Posterior and Anterior Vaginal & 21 \\
\hline Vaginal and Uterine & 8 \\
\hline Urinary Tract Infection ${ }^{a}$ & 14 \\
\hline Syphilis $^{a}$ & 1 \\
\hline Anemia $(\mathrm{Hg}<12 \mathrm{gm} / \mathrm{dl})^{\mathrm{a}}$ & 63 \\
\hline Obesity $\left(\text { Weight } / \text { Height }^{2}>25\right)^{b}$ & 43 \\
\hline High Blood Pressure (Diastolic $>90)^{b}$ & 18 \\
\hline Number of Women ${ }^{c}$ & 502 \\
\hline $\begin{array}{l}\text { Laboratory Test } \\
\text { Clinical Exam }\end{array}$ & \\
\hline
\end{tabular}

${ }^{9}$ Pachauri (1995), Hardee and Yount (1995), Fortney (1995), Elias (1996) and Hardee et al (1999), among others. 


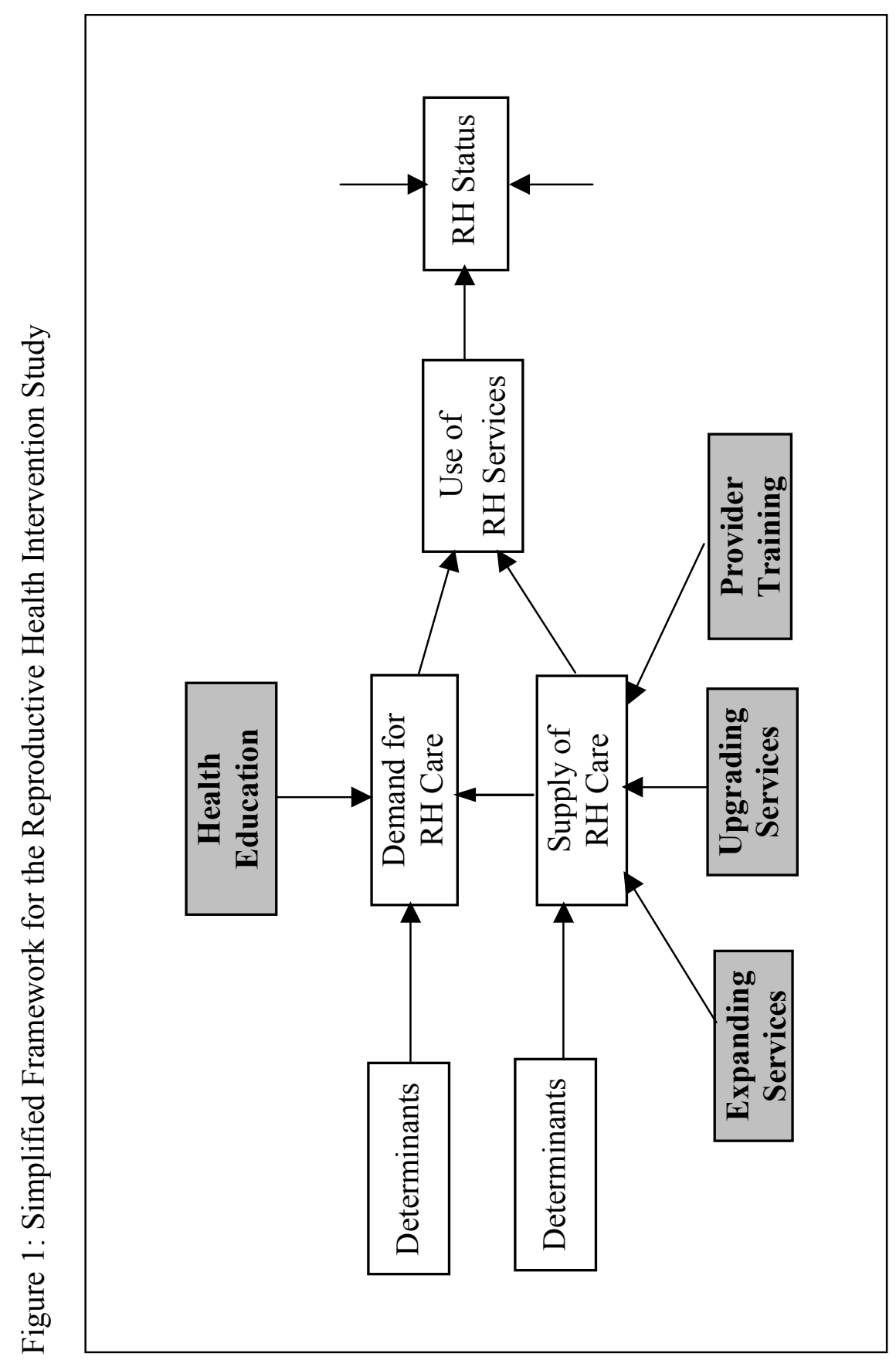




\section{What are the framework's main components?}

Figure 1 illustrates the intervention study's conceptual framework. The reproductive health status of the population is represented by the box entitled RH status on the diagram's extreme right. While recognizing that $\mathrm{RH}$ status is affected by a multitude of factors, our concern is with the reproductive health services available and with the factors that affect service uptake. Use of services is mainly the product of two constructs: the demand for care and its supply. These are in turn, affected by a myriad of sociocultural and physical factors, which for simplification in the diagram are labeled "Determinants". The shaded boxes in the diagram show the framework of intervention elements developed and implemented by the team: health education affecting the demand for reproductive health care, expansion and upgrading of services and provider training targeting its supply.

\section{What were the study's main objectives?}

I. On the supply side:

(a) To expand the reproductive health services available at the health centers. As will be described below, this involved bro dening what was offered to include new services, integrating he different service components, monitoring quality, strengthening management and organization, outreach and referral services and finally, ensuring the continuity of supplies.

(b) To carry out low-cost basic upgrading of ue physical environment, appropriate with this level of care.

(c) To train providers in technical as well as communicat on skills.

II. On the demand side, to conduct a community healtl awarenessraising education program for both women and men, with the aim of empowering women to understand and make de isions about their reproductive health.

III. To develop appropriate indicators and evaluatic n tools that could monitor the performance of the intervention's els nents.

IV. To transfer the lessons learned to the Ministry o: Health and Population 
Collaboration with the Ministry of Health and Population (MOHP) was established from the start. A Steering Committee was set up with senior policy makers from the relevant departments. The committee met regularly to review progress and make decisions regarding project activities. The framework of services that was ultimately designed was a result of this group effort.

\section{Where the work took place:}

The three primary care centers where the study team set about implementing the framework are in Giza, between 20 and $40 \mathrm{Kms}$ from Cairo. The centers are part of the national primary care coverage provided by the Ministry of Health and Population. Each was staffed with a female physician, an average of four nurses, a lab technician, a custodian, registrar and a health assistant. The centers routinely provide childhood immunizations and treatment for simple conditions. As far as services for women were concerned, these centers focused mainly on delivering family planning services, although antenatal and postpartum services were available, largely in theory but not in practice. Table 2 contrasts the study's proposed service framework with what was being offered at the primary level prior to the intervention. The services at these centers are heavily subsidized by the government. In the morning, patients are required to buy a LE 1 ticket $^{10}$, which should entitle them to an examination and free medication. After 11 am this fee is raised to $3 \mathrm{~L} . \mathrm{E}$, and after $1 \mathrm{pm}$ the doctor is allowed to charge fees which he or she can claim. ${ }^{11}$

${ }^{10}$ LE 1 the equivalent of USD $\$ 0.30$

${ }^{11}$ This system was developed to encourage doctors to work in rural areas. 


\section{How the team developed the framework: \\ The benefits of multidisciplinarity:}

The team examined every aspect of service delivery at the health centers over a period of several months at the start of the study. Healthcare utilization patterns and attitudes in the community were also looked at in depth. All of the issues identified were taken into consideration in the design of the service framework.

The process of developing the framework and deciding on which components to include and which to exclude was a lengthy one. It is important to point out that this process was very much enriched by the multidisciplinary make-up of the team. Composed of social scientists, clinicians, a bio-statistician and public health physicians, the team met weekly as a group throughout the lifetime of the study. All decisions were taken as a team, and the final framework benefited from the contribution of each member based on his or her discipline.

The social scientists for example brought their expertise to discussions on the framework's medical components as well as to the content of the physicians' training course and similarly, the physicians contributed to the content of the health education program. The baseline survey tools as well as those specially developed for monitoring and evaluation were likewise designed and reviewed by the whole team and each member naturally brought his or her background to the interpretation of findings and results.

\section{The benefits of the MOHP's input:}

The process of developing the framework benefited greatly from the input of the MOHP staff, at the central, district and health unit levels. The Steering Committee reviewed the framework design and was instrumental to problem-solving. District-level MOHP staff were crucial with regards to logistics. The health unit providers' input on which elements could be offered at this level of care was essential to the process. 
8

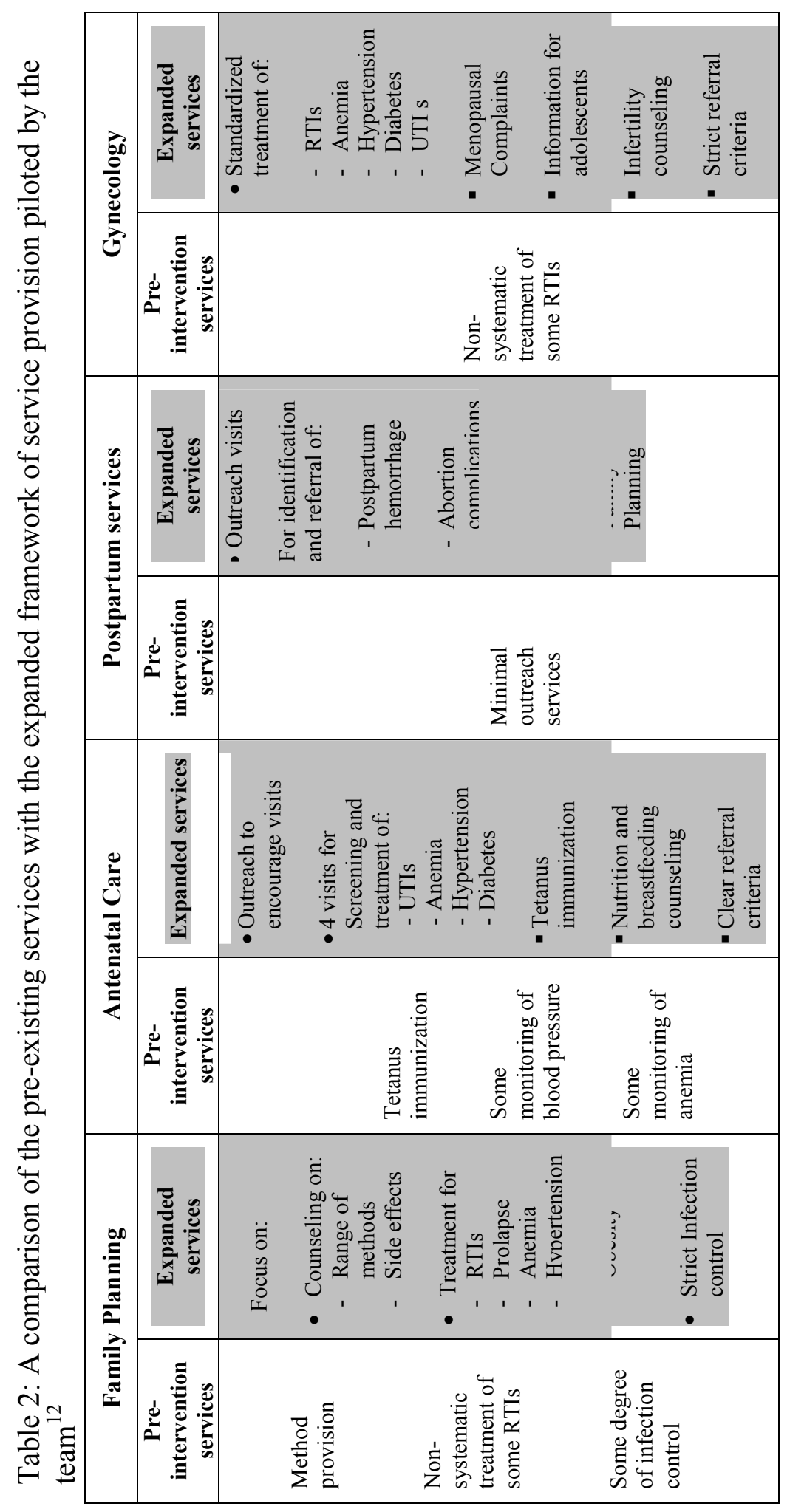

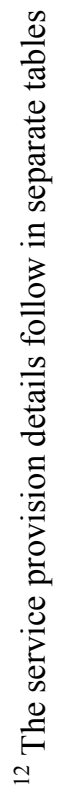


The framework that was developed:

\section{A. The Supply side}

1. Component One: Expanding Reproductive Health Services:

1.1 Providing what is lacking: Broadening the scope of services available in order to better address women's reproductive health needs ${ }^{13}$ :

The team conducted a baseline survey that showed that the primary clinic services for women are in the main limited to family planning and rudimentary MCH services, as illustrated in Table 2.

Family planning services are part of a vigorous, vertically funded program, which until recently focused on recruitment of new acceptors. ${ }^{14}$ The $\mathrm{MCH}$ services, while comprehensive in theory, were in practice limited to rudimentary antenatal services, which in turn, focus on tetanus immunization for pregnant women, a common situation in many developing countries. No systematized services were available for minor gynecological complaints. It becomes clear when these activities are compared to the documented burden of disease in these communities, that there is considerable unmet need for a range of on-site services addressing conditions such as reproductive tract infections ${ }^{15}$, as well as for referral services to offsite secondary centers for more complex conditions such as advanced prolapse and resistant RTIs, for example. It must be emphasized that service elements described in this paper and itemized in Tables 3, 4 and 5 were selected on the basis of their suitability for a primary care level facility.

\footnotetext{
${ }^{13}$ For a detailed rationale of the service items selected for inclusion, please refer to the forthcoming RHWG monograph on the framework's medical components by Younis et al (2000).

${ }^{14}$ Contraceptive use in Egypt is largely dominated by the IUD, according to the 1995 EDHS (El-Zanaty, 1996).

${ }^{15}$ RTIs are associated with fetal wastage, low birth weight and congenital infections. These in turn contribute to high neonatal and infant mortality rates and are the cause of significant morbidity. Evidence also suggests that the risk of HIV transmission is increased in the presence of some RTIs. Infection of the upper reproductive tract by RTIs results in pelvic inflammatory disease, which in turn can lead to infertility, ectopic pregnancy and chronic pain. RTIs also have an impact on family planning programs, both in the sense of increasing demand as well as resulting in discontinuation of methods, if the RTIs are perceived as "side effects" of usage (Elias, 1996).
} 
Antenatal and postpartum services:

The team focused on the essential antenatal care services that could be given at this level and these are shown in Table 3. Deliveries are not performed within primary care, and for this reason were not addressed in the intervention framework. Anemia was highlighted for example because it was one of the more prevalent and often severe conditions documented by the earlier Giza study. Postpartum services were also emphasized. The left-hand column of Table 3 lists the antenatal and postpartum service components selected for inclusion. The top row of the table lists the service elements that can be offered for each component selected, at this level of health provision. 


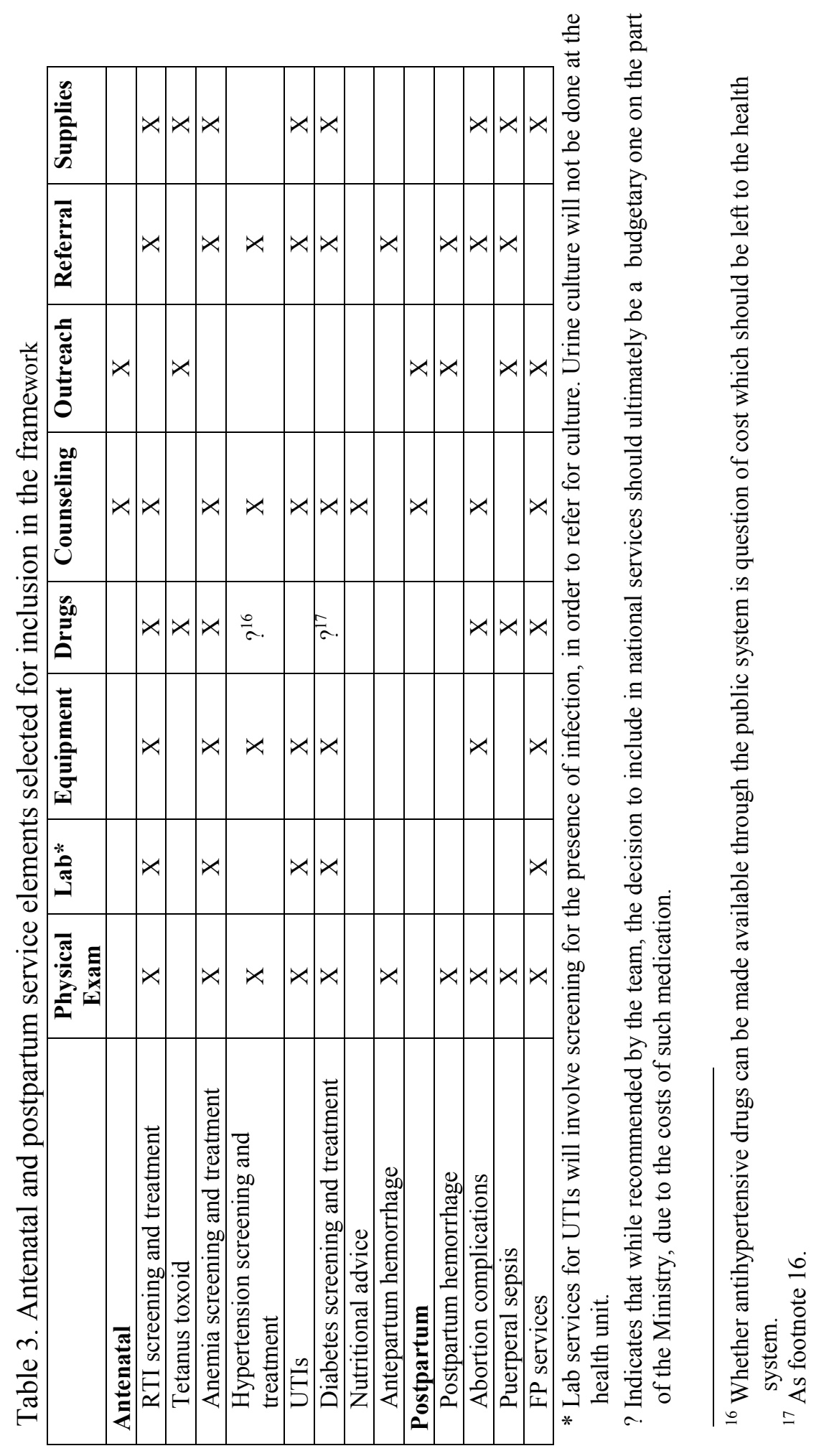


Services for gynecological and related complaints:

Since services for minor gynecological conditions were not offered at this level of service delivery, in spite of being highly prevalent, the team focused on introducing low-cost diagnosis and treatment/referral facilities. As with the other services, the team based its selection of what conditions to address on what the earlier Giza study had documented as being prevalent in the community. The services selected therefore include diagnosis and treatment of the most common reproductive tract infections (like monilia and trichomonas for example), diagnosis and referral for prolapse and counseling and referral if necessary for infertility. ${ }^{18}$ Table 4 lists the service elements piloted to address each type of condition. A question mark in the box for hypertension and diabetes drugs is to indicate that their provision is recommended but is ultimately dependent on the clinics' budgetary limitations.

${ }^{18}$ While the Giza study did not document a high level of actual infertility the ethnographic work revealed a huge concern with perceived infertility as well as a large burden upon the services often resulting in inappropriate and unnecessary treatment. 


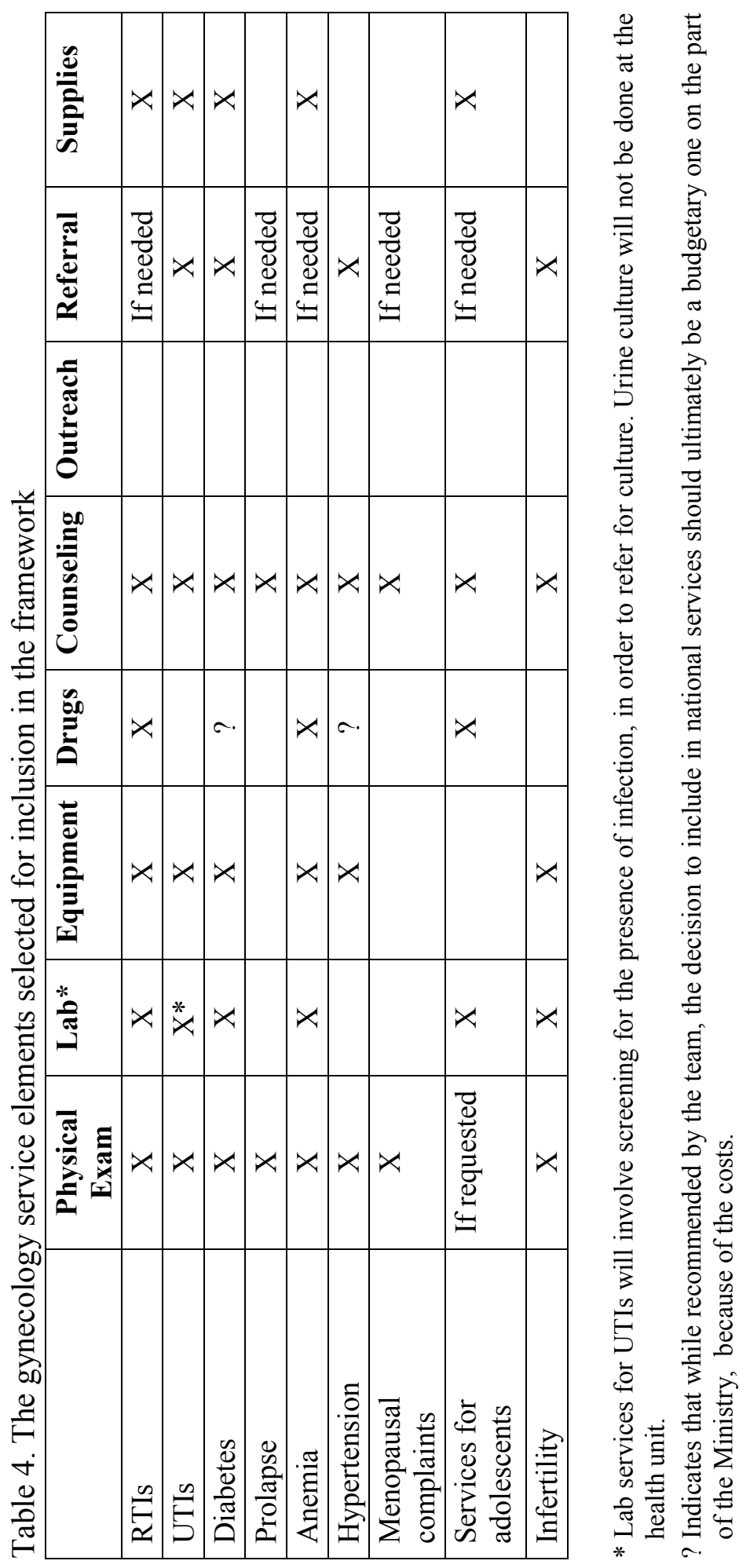




\section{Family planning services}

Care was taken so as not to duplicate the successful MOHP family planning services already in place. The study therefore focused on three items; counseling, screening and infection control. Table 5 shows the service components required for each type of activity.

\subsection{Integrating services:}

\section{Broadening providers' technical competence to offer multiple} services:

Broadening providers' knowledge and technical competence gives them the skills they need to address different reproductive health problems at the same time and results in more integrated and more comprehensive services. This also helps sustainability by ensuring the continuity of services in the event of staff turnover. However, care must be taken not to overburden staff, and monitoring, supervision and technical support are essential.

\section{The value of simple yet comprehensive medical records}

The team found that the different services provided at the primary care center were largely un-integrated even though they were often offered by the same provider. An illustration of this was the record-keeping system, where records for $\mathrm{MCH}$ and family planning services are kept separately, usually in different rooms within the health center. This is a common reflection of separate vertical programs that administer different services in many countries and is not limited to the Egyptian primary care system. However, it has a large impact on both the quality of care that women receive and its comprehensiveness, since a woman attending on separate occasions for antenatal care, postpartum services and family planning would have each visit recorded in a separate record in a separate location. Moreover, the information collected was mainly for statistical reporting purposes. This by definition prevents the provider from reflecting on the woman's history and condition as a whole. Since the reproductive health approach views women holistically, one way of ensuring this would be to develop a simple medical record system that would keep all the information in one place and not focus on statistical reporting at the expense of the clinical picture and case management. 


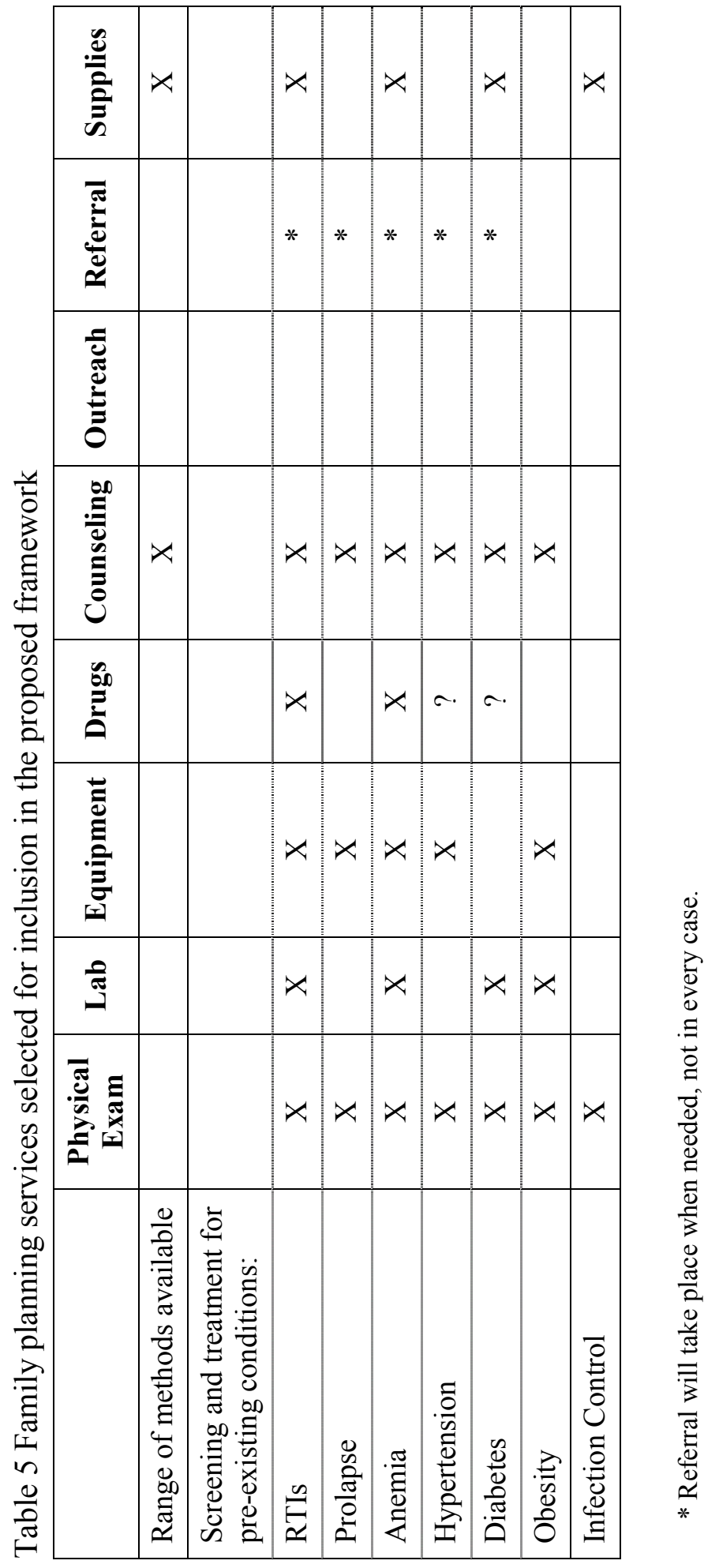


To do this, the team spent a considerable amount of time first designing and then piloting a simple medical record system. The aim was to have a single, double-sided sheet of paper for each woman, divided into sections and columns according to the different services (antenatal care or family planning for example) and with spaces for several visits, so that the resolution or progression of a complaint could be viewed over time. The record included spaces for the complaint, a checklist of signs and symptoms, diagnosis, treatment and referral. ${ }^{19}$. An example is attached as an appendix to this paper.

\subsection{Setting standards for care}

The team's baseline observations of how services were being delivered showed that there was much room for improvement in a wide range of areas. For example, provider/client interactions were often extremely brief, as short as a couple of minutes in many instances and mainly limited to verbal questioning. The providers often neglected to listen to the clients and also didn't usually encourage them to ask questions. The providers also often didn't explain treatment regimens properly or attempted to make sure that the clients understood them. Lack of privacy was also a problem. All of these items imply a certain lack of respect for clients, an issue which the social component of the study tried very hard to address, since it is such an important aspect of the reproductive health approach. Sanitary practices were often not followed in examinations, and the overall hygiene of the health centers was very poor. This is why the team worked to develop standardized procedures for diagnosis and treatment as well as for general cleanliness and hygiene.

\subsection{Improving management and organization:}

The initial observations also showed that it was necessary to address organizational and management issues. While the personnel in each health center were not numerous, precise job descriptions and division of responsibilities were not followed, particularly among nursing staff. Attendance was irregular in some cases and punctuality was a problem. The providers were in effect managers of their health units, but had not been given any management training prior to their appointments.

\footnotetext{
${ }^{19}$ For a thorough discussion of the medical record developed, please refer to the forthcoming Intervention Study manual on monitoring tools by Galal et al.
} 


\subsection{Ensuring the availability of supplies:}

This is difficult to ensure, particularly in a system where the physicians are not given managerial training prior to taking up their responsibilities. For example, supplies of medication were delivered to the unit irregularly, and this affected service uptake to a large extent. The team explored various possibilities to ensure the regular supply of the necessary solutions and basic equipment such as slides and disposable gloves, for example, that were recommended by the team and that are not yet part of the Ministry's infrastructure.

\subsection{Strengthening linkages to other levels:}

An effective two-way referral system to higher treatment levels is always essential to the success of primary services. For this reason, the team spent a considerable amount of time establishing links with secondary centers, namely local district hospitals that are within easy geographical reach by clinic users. Stress was placed on feedback to the primary provider after the referral visit and was seen as crucial. The providers were trained on referral criteria and referral cards were designed with their input and made available.

\subsection{Going out to the community with outreach services}

The nurses were also trained on how to take outreach services to the community. A series of training sessions covering antenatal, delivery, newborn and postpartum services were held with discussion of communication styles in order to show nurses:

- How to be prepared for home visits

- How to use simple language, be properly dressed and be sensitive to the household.

- How to make mental notes and avoid writing down observations during the visit itself. ${ }^{20}$

\section{Component Two: Provider Training - The main principles}

Three principles were very important: The first was recognizing that it was necessary to train all the providers working at the centers and not just the doctors; the second was that the main part of the training be conducted on-site, and finally, that it emphasize the social aspects of service provision such as communication and the importance of being sensitive to women's social context as well as basic technical issues.

${ }^{20}$ For more details please refer to the Intervention Study manual on outreach services by Khattab et al. (2000) 


\section{Who was trained?}

The doctors at this level of care are typically general practitioners. They usually have several years' experience, before they are put in charge of a health center. They have access to in-service courses on family planning, control of diarrheal diseases and oral rehydration therapy, and management of acute respiratory infections. The doctors trained by the team had at least ten years of experience, on average and had been exposed to all of these courses. The team trained physicians, nurses, laboratory technicians and custodians, all on-site. The doctors also received 12 days of training at the out-patient clinic of a major urban teaching hospital. As mentioned above, the overall objectives were to increase the providers' understanding of reproductive health as a holistic concept, to train them how to provide the added services and how to approach different medical conditions from a social standpoint as well as medically.

\section{Who did the training?}

The technical training for each type of provider was done by specialists in that field. Obstetricians/gynecologists on the team trained the doctors. Senior nursing consultants trained the nurses and the lab technicians were trained by a physician as well as by a technician with several years' experience. The social scientists on the team trained all the providers on the social aspects of service provision that they should take into account.

\section{What did the providers training cover?}

\section{a) The importance of the social context:}

For all the providers the training course highlighted the importance of listening and encouraging women to ask questions. Sensitivity to rural traditions, women's workload, social circumstances, customs and the woman's right to privacy and counseling were stressed. The social training also exposed the providers to women's perceptions of health and health provision.

b) Technical aspects of their work:

i. For doctors:

- Diagnosis, management and follow-up of simple gynecological conditions that can be addressed at the primary care level.

- Antenatal management; stressing the early diagnosis of high risk factors in pregnancy and the referral of high-risk cases, based on a minimum of four antenatal visits per pregnancy.

- Family planning counseling and infection control. 
- Referral criteria

- Filling in and retrieving medical records

- Counseling and communication

ii. For Nurses:

- Technical training on the nurses' role in antenatal care, family planning and gynecological service provision.

- Hygiene in general and sterilization in particular

- How to keep records and register case histories

- How to do outreach visits

- How to give health education messages

- How to communicate better with patients

iii. For laboratory technicians:

Since every health center in Egypt has a basic lab and a lab technician, the team made a decision early in the study to rely on actual laboratory diagnostics to identify RTIs instead of syndromic management ${ }^{21}$. The objective was to train the technicians to be able to do simple procedures such as diagnose common RTIs with a light microscope, analyze urine, estimate blood hemoglobin and sugar levels, and carry out pregnancy tests and rhesus typing. Involving technicians has the added benefit of not overloading physicians with these procedures.

The initial training was followed by on-site refresher sessions, twice weekly, for three months. After a monitoring period, the weak points that remained were addressed by a further course of twice weekly visits for another two.

\section{Component Three: Upgrading the physical infrastructure and} providing equipment

- The physical infrastructure:

The health centers were in need of much basic physical repair. The team took care that any improvements or additions to the physical infrastructure corresponded with the primary care level of the clinics. It was very important that changes be as low-cost as possible so that

\footnotetext{
${ }^{21}$ For a discussion of the arguments for and against syndromic management of reproductive tract infection, please refer to Mamdani (1999).
} 
they would be eventually feasible for the Ministry of Health and Population to replicate on a larger scale.

The physical upgrading involved items such as providing the examination rooms with a coat of paint, making sure that the plumbing and electricity were working, that the examination beds had screens for privacy and that there was netting on the windows to keep out flies and mosquitoes. Work surfaces in the lab were tiled. Much of the physical upgrading costs was covered by community participation, in the form of individual donations.

- Equipment needs:

The kind of equipment needed to provide the services outlined in the study team's framework is quite basic and is easily found in most primary level clinics. Usually the problem is one of maintenance rather than buying expensive apparatus. The team examined and tested all of the equipment like sterilizers, microscopes and speculae. Lenses for the light microscopes were replaced with new ones found in storage, and glass slides and slide covers were provided. The Ministry of Health and Population provided most of the needed equipment to the three health centers from its stores and the smaller portion that remained was purchased by the study. Ultimately, the study provided sterilizers and cleaning supplies.

\section{B. The Demand side: Health Education and Awareness-Raising}

\section{Are women aware of reproductive health conditions?}

The team's earlier work had showed that not only did women have an unexpectedly high level of reproductive disease, they also had very low level of health awareness and a very low level of healthcare uptake ${ }^{22}$. Services don't function in isolation of demand and for this reason the team decided that a health awareness-raising program needed to be an essential part of the framework. The team was very aware of the social, cultural and economic constraints in women's lives that affect their ability to access healthcare, however it was nevertheless strongly felt that health education would give women information empowering them to make decisions. Health educators from the MOHP were trained by the social scientists on the team, using a participatory approach. ${ }^{23}$

${ }^{22}$ Khattab et al. (1996).

${ }^{23}$ For a detailed description please refer to the Intervention Study policy paper on the health education component., by Khattab et al. (1999). 


\section{What the health education program aimed to do:}

- Raise women's and men's awareness about their health in general and about their reproductive health in particular.

- Empower women with information to make decisions regarding their health.

- Train Ministry of Health and Population personnel in communitylevel reproductive health education, as part of the handing-over of the framework and so as to encourage sustainability.

A series of short, specific health messages, in simple, locally appropriate language, was developed and conducted in the field by the anthropologist and her field team to:

- Help women reorganize their priorities with regards to their health in general.

- Help women recognize symptoms of reproductive morbidities.

- Encourage women to seek medical advice whenever needed

- Help empower women to make their own decisions concerning their health.

- Encourage women to create an effective networking system

- To foster confidence among women that their contribution at home and in the community is essential and worthwhile and should be appreciated.

Messages were also prepared for men, policy-makers and service providers. 


\section{Sequence of the activities:}

1. A baseline survey of the situation at the service del rery points and in the community over a nine month period was the $t$ am's first task. This documented how services were being provide $I$ at the health centers and was necessary to understand the comr unity's healthrelated behaviors and health care utilization patterns The team was careful to collect both qualitative and quantitative dat . This baseline assessment involved extensive facility-based observ tion of actual service delivery, observation of encounters, a c nsus of user characteristics, provider interviews, a client satisfactir a survey and a cost study assessing the cost of services per user to he Ministry of Health. The physical environment and upgrading $\mathrm{n}$ eds were also explored. The community-based data collection includ $\mathrm{d}$ a householdbased women survey which documented the socio-ec nomic context, reproductive history, reported reproductive morbic ty and health utilization patterns. The team also carried out inter iews with key informants in the community, focus group discussions.

\section{Design and development of the framework}

At the same time, the team worked on the selection ( : which service components would be appropriate for inclusion in a reproductive health framework at this level of healthcare. This nvolved many months of examination of several issues:

a) The documented reproductive health needs at the cc nmunity level.

b) The actual services being provided.

c) The gaps between the needs and services: determ nation of what elements could to be added to the service mix at $\mathrm{t}$ ₹ primary level and in what form they should be delivered.

d) A thorough study of the feasibility of providing such expanded services, taking acceptability, training neec, costs and sustainability into account

e) The training needed for the different types of provic :rs.

f) Design of low-cost, basic upgrading of the physical nvironment.

g) Design of the health education component

h) Design of monitoring tools to evaluate the process

June 96 - 


\section{Implementation in the field}

The actual implementation of the different compone ts in the field took place in the winter of 1997 and the spring and c irly summer of 1998. The health education program was initiated ${ }^{24}$ nd carried out over a period of seven months, after a pre-test of hea $h$ awareness in the community. The training of the different types of providers took place during this period ${ }^{25}$. The low-cost upgrading if the physical environment was completed ${ }^{26}$ and the participation of the community in the process was initiated.

4. Monitoring and retraining: In January 1998, the team began to monitor the performance of the different components it the field, using specially designed observation tools and checklists. Tl s phase took 5 months. After analysis, two months of retraining was $\mathrm{c}$ rried out at the health centers to address the problems identified.

\section{Evaluation and analysis}

The final evaluation of the performance of the differ nt intervention components was carried out during the winter of $1798-99$ for the period of 6 months. The team then started to analyze nd disseminate the findings and that is still ongoing at the time of writ: $\mathrm{lg}$. Manuals for each of the framework's components are being pri duced, so that others can replicate the experience, in addition tc policy papers detailing various aspects of the work.

\footnotetext{
${ }^{24}$ For a more detailed discussion of the process of designing and testing the monitoring and evaluation tools and process indicators developed, please refer to the forthcoming RHWG monograph on indicators by Zurayk at al.

${ }^{25}$ For a detailed description of the contents and process of the provider training, please refer to the study manuals.

${ }^{26}$ For a detailed description of the upgrading process, please refer to the specialized study manual on facility upgrading.
} 


\section{Monitoring and Evaluation:}

\section{Monitoring tools:}

Once the physical upgrading was finished and the equipment was in place, the providers were trained and the health education program was carried out, the framework was essentially in place. In order to examine its performance, the team developed and then tested monitoring tools to monitor and evaluate every component of the work. Different checklists were developed for each type of provider and separate tools were designed for observations, patient flow and facility readiness.

\section{How was the monitoring done?}

The team then began monitoring service delivery and user characteristics at the health centers, through regular observations by the field researchers and the team physicians. They collected both qualitative and quantitative information, using observation checklists they had developed.

The health education program was evaluated by a pre and post-test of health awareness, as well as by feedback from the trainers during the participatory training process.

The checklists the team developed for the baseline survey of the original situation at the health centers were further refined to record every aspect of the expanded services. These were then used in monitoring and evaluating. The different trainers used these checklists to observe and record every aspect of providers' performance, on-site. By breaking down the different providers' responsibilities into discrete steps and observing service delivery, the team captured details of the different elements of the services' performance They tried to be unobtrusive and not disturb the providers' daily activities. It was important not to write down information during the observations, but to do that afterwards, discreetly. The providers were told that the purpose of the observations was to help identify any problems and aid in their solution.

The observers rotated between the health centers and took care not to interfere in encounters even when faulty procedures were observed. Special feedback sessions were subsequently scheduled for that purpose.

Data was also collected from the community by interviewing clinic users as well as non-users, to complement the information collected at the facility, document utilization patterns and also to help evaluate the impact of the health education component. 
The different tools developed by the team for monitoring and evaluation are shown in Table 6. Process indicators were selected and are described in detail, together with the tools themselves in a forthcoming publication.

Table 6. Monitoring tools used at the different stages

\begin{tabular}{|c|c|c|c|}
\hline & $\begin{array}{c}\text { Baseline } \\
\text { Survey }\end{array}$ & Monitoring & Evaluation \\
\hline $\begin{array}{l}\text { 1. Community } \\
\text { - Women Home Interviews } \\
\text { - Interviews with Key Informants } \\
\text { - Focus Groups } \\
\text { - Health Education (initial survey } \\
\text { and post-test at evaluation) }\end{array}$ & $\begin{array}{l}\sqrt{ } \\
\sqrt{ } \\
\sqrt{ } \\
\sqrt{ }\end{array}$ & & $\sqrt{ }$ \\
\hline $\begin{array}{l}\text { 2. Health Center } \\
\text { - User Characteristics } \\
\text { - Patient/Physician Encounter } \\
\text { Observations } \\
\text { - Facility Observation (Patients' } \\
\text { Load \& Health Center } \\
\text { Cleanliness) } \\
\text { - Nurses Observation of technical } \\
\text { - skills } \\
\text { - Nurses Observation of general } \\
\text { - } \text { responsibilities } \\
\text { - Exoviders Interview } \\
\text { - Coxit Interviews } \\
\text { - Medical Records }\end{array}$ & $\begin{array}{l}27 \\
28 \\
\sqrt{ } \\
\sqrt{ } \\
\sqrt{ } \\
31\end{array}$ & $\begin{array}{l}\sqrt{ } \\
\sqrt{ } \\
\sqrt{ } \\
\sqrt{ } \\
\sqrt{ } \\
29 \\
30 \\
\sqrt{ }\end{array}$ & $\begin{array}{l}\sqrt{ } \\
\sqrt{ } \\
\sqrt{ }\end{array}$ \\
\hline
\end{tabular}

${ }^{27}$ The nurses technical skills were observed during the baseline phase, but without using an itemized checklist.

${ }^{28}$ As the previous footnote.

${ }^{29}$ The provider interview was not repeated because its main objective was to understand the administrative setup of the health center. Once this was known, there was no need for repetition. Also, the ongoing dialogue that developed between the team and the health center staff provided continuous information on other issues that were part of the original interview.

${ }^{30}$ These were not repeated and the information was collected by home interviews instead.

${ }^{31}$ This refers to the performance of the medical record developed by the team. It did not exist at baseline. 
What the monitoring exercise showed:

While the monitoring process showed general improvement, it also identified areas that required more attention and training. After retraining, the evaluation showed a degree of improvement across almost all the indicators applied. These changes ranged between quite substantial improvement in some areas and less in others, as described below. In general, the cleanliness of the centers and sterilization of instruments were two of the areas that showed a large improvement. The monitoring also showed that new services such as RTI diagnosis and treatment could be technically provided and were very acceptable and appreciated by the users. The providers' social skills also showed a marked improvement. Some issues remained problematic, as will be explained below.

\section{Evaluation: Feasibility and not impact}

The difficulty of attributing impact:

From the study's outset, the team decided not to try to document the service framework's potential impact on the health status of the community. Trying to document impact is problematic when interventions are aimed at entire communities which are influenced by many different physical, social and cultural variables. Health service utilization, which the team addressed, is but one factor among these. To associate a change in health status (or its absence) with the framework would be to ignore the role of many confounding variables which also affect health at the community level. While it is generally accepted that such services do have a positive effect on women's reproductive health, such an effect is difficult to quantify.

Documenting process and outcome:

The objective was not to measure performance against quantitative targets. Focusing exclusively on quantitative targets is all too often at the expense of quality and for this reason the team did not put its emphasis on quantitative outcome indicators against which to measure the performance of the different components. The team instead focussed on process indicators (also sometimes called intermediate outputs) in an attempt to understand the different factors that affect the feasibility of offering these services at the primary clinics. 
The important changes and the lessons learned are outlined below:

\section{Positive changes:}

1. The demand for reproductive health services increased: The proportion of women attending the services for reproductive health complaints increased in all three centers. ${ }^{32}$

2. Women appreciated the new services: as users became used to onsite lab analysis and treatment for RTIs for example, they showed their interest in having these services and began to demand them.

3. Women waited less and had more contact time: The ratio of the total time women spent at the health center to the time spent in actual contact with the physician improved. The time spent waiting for services decreased and the time with the provider was found to be at least double what it had been at baseline.

4. The quality of the care improved: The doctors were more sensitive to women's privacy. History-taking was more complete, examination procedures improved dramatically, as did appropriate diagnoses and information exchange during the encounter.

5. The providers came to feel the value of keeping individual records for the clients, and appreciated their value in keeping track of women's case histories over time.

6. Nurses' performance improved: The nurses assisted the doctors more and they became markedly more enthusiastic about their jobs.

7. Infection control improved: Instrument sterilization procedures in particular showed a very substantial and consistent improvement.

8. Lab technicians were trained to do reproductive tract infection identification: The provision of simple diagnostics for reproductive tract infections is technically feasible at this level of service delivery, provided that basic training is given to the technicians

9. On-site lab diagnostics were valuable: Having the lab technician aid diagnosis by identifying various reproductive tract infections improved the quality of care given and case management. ${ }^{33}$

${ }^{32}$ Although this increase dropped to some extent in the evaluation phase, this was explained by its coinciding with annual school-entry, a period when healthcare utilization generally decreases across the board.

${ }^{33}$ Given the generally satisfactory performance of the lab technicians and their ability to accurately identify the most common RTI pathogens, the presence of simple lab diagnostics was found to be preferable to using the syndromic algorithm approach with its generally poor predictive value. 
10. The centers were cleaner: Hygienic conditions in general were found to be markedly for the better, at all three centers.

11. The health education program was effective: Health education very quickly affected the demand for reproductive health services and addressed a very real need in the community.

\section{What did we learn?}

- A simple framework of essential reproductive health services can be provided at the primary care level.

- These should include treatment for simple gynecological conditions, family planning, antenatal and postpartum care.

- These services are very much needed and appreciated by users.

- The doctors providing these services don't have to be specialists.

- The doctors can learn new procedures even if they are used to providing the same services for years

- Nurses can be very responsive to the new services and eager to participate.

- The technicians already working at the centers can learn and carry out simple lab work for reproductive health conditions.

- The centers don't need a lot of new equipment in order to offer reproductive health services.

- The equipment that is needed is neither expensive nor sophisticated.

- The physical upgrading that is needed to provide these services is both basic and inexpensive.

- Using a carefully designed, integrated medical record, with spaces for sequential visits gives providers a perspective on the client's history, which results in better quality of care.

- Medical records that are designed for statistical collection rather than focusing on the individual clinical picture do not help the clinicians in case management.

- The increased utilization of the centers means more income for the providers.

- Increased caseload can be overcome by improving managerial skills and team work to a large extent.

- There is a huge amount of interest among providers and supervisors in having management training. 
- The availability of free or subsidized medication is an important factor in women's decision-making to utilize the services. ${ }^{34}$

- The involvement of the providers in decision-making is essential, and ideally they should have more managerial autonomy.

- Carefully done health education does improve health awareness and gives women information which enables then to make decisions regarding their health.

- MOHP health education staff, used to delivering family planning messages, can be successfully re-trained to give reproductive health information and can act as trainers themselves.

\section{Challenges}

Designing and implementing the reproductive health framework was not without its conceptual and logistical challenges.

I. Designing the framework was conceptually challenging, since it meant selecting, from a very broad range of services, just those that would both address women's needs and yet be deliverable at the primary level. Many factors were taken into consideration in order to arrive at the components outlined above.

\section{The logistical issues that were most challenging are described below:}

\section{Health center management issues:}

The physicians working in these health centers are much more than service providers. They also manage the health center and deal with all the issues that arise relating to supplies, maintenance and staffing problems. To a certain extent, management issues presented a challenge to the team:

i)Ensuring the continuity of supplies was problematic. The supplies needed for the diagnosis and treatment of RTIs (for example) were not part of the MOHP system. The team explored various possibilities to ensure the regular supply of the necessary solutions and basic equipment such as slides and disposable gloves. One of the options explored was to set aside a portion of the laboratory income from certain tests to purchase the necessary materials needed to keep the lab running. The MOHP solved the problem of

\footnotetext{
${ }^{34}$ The study team developed a list of low-cost medications for the most prevalent RTIs. The Ministry of Health and Population agreed to add these to the list of essential drugs routinely provided to the primary care level units on a national basis. Delivery is currently dependent on budgetary availability.
} 
medications for reproductive health conditions by offering to incorporate the list of drugs suggested by the team into its essential drugs list. (The supply of these medications has been somewhat irregular, however)

ii) Administrative issues such as maintenance delays created more stumbling blocks for quality service provision than questions of technical skill, and this was true at all level of providers. (For example: the sterilizer in one of the units was not used because the electrical outlet was burnt out and this was not addressed for some time. In another instance a malfunctioning drain in the lab meant that lab services were suspended for a time).

iii)Staffing problems such as punctuality, lack of job descriptions and appropriate attire occasionally arose.

Because problems occasionally arose due to poor decision-making, the team felt that the physicians would benefit greatly from a short course in management. This met with great interest.

\section{Training:}

While the training of the providers was successful in many cases, this was not always true. Some staff needed more retraining than others. This raises the issue of the amount of retraining that is necessary to reach acceptable levels of performance, of who should train and the associated costs.

\section{Ensuring that the referral system functioned adequately}

In spite of the team's efforts, the two-way referral system did not function satisfactorily. This was not seen to be due to the referral scheme's conception as much as to bureaucracy at the secondary referral centers. The referral system as a whole would probably be more successful in the scaling-up phase, which is planned to involve 14 health centers in a single district, affiliated with two hospitals.

\section{Motivation issues:}

While some of the providers were very motivated, this was not true in all cases. Careful thought has to be given to the issue of provider motivation in any attempt to broaden their duties and responsibilities. Within the Egyptian MOHP system, physicians are allowed to keep a certain proportion of the earnings, which they divide among the different providers at the clinic. The team found that once the service 
framework was in place, the utilization increased, increasing with it the providers' incomes. This proved to be a good motivating factor.

\section{Supervision issues}

For the framework to perform adequately, strict supervision is required from the district level. The team had the full backing of senior policy makers at the central and governorate level. However, turnover at the district level was high. It is expected that the district supervisors will become much more involved in the scaling up phase.

III. Monitoring the cost of the framework:

One of the issues that the team was concerned with was the question of the framework's cost to the services, and the implications that would have for both feasibility and sustainability. In order to assess what the eventual costs of delivering such services would be to the Ministry of Health and Population, the team documented the costs of the existing services, over a financial year, to the Ministry. This exercise was repeated after the service framework was in place. At the baseline the team documented that the average cost per user at the three health centers (to the MOHP) was LE 7.1. Once the framework was in place, the average cost of services per user (again at the three health centers) was found to be L.E 7.4. The stability of the cost was felt to be largely due to a substantial increase in users. However, the drug supply was not and is still not at the time of writing, consistent, making estimation of the actual running costs of the framework over a financial year difficult. It is expected that the costs to the MOHP will increase substantially once drugs and replenishables needed for RH services are supplied regularly.

As mentioned, this estimate refers to what running such a service framework would in theory cost a public health service. It does not include the cost of the team's contribution to the framework's development. It also does not include the costs of the health education component or what a comprehensive training program would cost. 


\section{Policy Implications}

The overall favorable performance of the framework that the team developed should encourage policy makers to integrate basic reproductive health services within primary level services. The team's experience has significant implications for the way primary care services are conceptualized and delivered in developing countries.

Services will need to be redesigned in order to provide this more womencentered approach. The framework described here was conceptualized in response to the local needs in Giza. It should be easily adaptable to other governorates in Egypt as well as to other developing countries. In order to disseminate the experience and aid others interested in expanding primary care service to address common reproductive health problems, the team has produced manuals describing the framework's different components, as shown below.

The implications for training are significant. If such frameworks are in place, future generations of physicians and nurses will automatically enter into a new system similar to the one described. For the present however, the system will have to allow for training of currently practicing providers in order for them to be able to deliver the services.

Primary care systems can also take advantage of staff already present who can do new tasks. Lab technicians are employed at these facilities and their presence can be taken advantage of. The teams' experience showed that with a minimum of training, lab technicians can perform the simple diagnostic tests quite satisfactorily, and are mostly enthusiastic to do so. ${ }^{35}$

The experience also has implications for the way services are monitored and supervised. These have to date largely focused on quantitative targets, an overemphasis which can detract from focusing on the client and on the service provision process itself. Efforts are underway in different parts of the world to develop new indicators that focus on individuals' needs and on service quality. Systems will need to adapt to take advantage of these new methodologies as they develop. Providers as well as supervisors will need to be trained in how to use these new tools to assess progress. Checklists and monitoring tools would be

\footnotetext{
${ }^{35}$ Similar findings support satisfactory performance of technicians at this level following basic training. Khan, M.E., et al.(1998).
} 
needed and it is hoped that the ones developed by the team can be adapted for this purpose by others ${ }^{36}$.

The study team's experience also has implications for management at the health center level. The ICPD +5 review of global progress in implementing the reproductive health approach 37 showed that management skills are very much needed at all levels of health systems, but particularly at the lower ones. The study team certainly found that decentralizing decision-making and problem solving would help address some of the more intractable managerial obstacles facing service provision. Greater flexibility in resource allocation and the input of local providers in the estimation of needed supplies and their ability to organize maintenance issues would contribute greatly to resolving simple but recurrent problems that hinder quality service provision. However, decentralizing decision-making does require considerable management capabilities and efficient structures linking the different levels within the system. While the global evidence (ibid) indicates that the success of decentralization efforts is still mixed, steps to minimize bureaucratic obstacles are very much needed.

Egypt is currently in the planning stage of a large-scale reform of its health sector which will involve some degree of decentralization. It is hoped that reproductive health will be a priority within the constellation of essential services being selected by the health sector reform process ${ }^{38}$.

The group's experience also suggests that in-depth health education has a larger role to play raising health awareness. Participatory training methods, are recommended.

${ }^{36}$ Galal et al. (forthcoming)

${ }^{37}$ Catino, J. (1999).

${ }^{38}$ A rationale for including reproductive health services within health sector reform is discussed in El-Adawy, M., and Khalil, K. (1998). 


\section{Looking Ahead: The Next Step}

The team is currently expanding its experience to a larger number of health centers. This stage involves fifteen service delivery points in Giza, based on the suggestion of the MOHP. District-level specialists are the trainers for various aspects of the framework. This scaling up stage involves the training of service providers at the health center level as well as the training of district level supervisors on the monitoring tools developed by the team. While the team's experience in three initial health centers has been very encouraging, the true test of the framework's performance lies in the evaluation of the next phase.

\section{Manuals produced by the Reproductive Health Intervention Study}

- Physical Upgrading required for reproductive health services

- Reproductive health service protocol for physicians

- Physician training manual for reproductive health services

- Nurses service protocol

- Reproductive health referral manual for physicians at the primary care level

- Monitoring tools and indicators for reproductive health services

- Community-based health education messages for reproductive health

- Health education manual

- Nurses outreach manual 


\section{REFERENCES}

Catino, J. (1999). Meeting the Cairo Challenge: Progress in Sexual and Reproductive Health. Implementing the ICPD Program of Action. Family Care International.

Chowdhury, S.N.M., Y.H. Ahmed, E. Karim, A.E. Masum. (1995). “A Study to Determine the Prevalence of Reproductive Tract Infections Among Health Care Users of a Bangladesh Women's Health Coalition Clinic" BWHC, Dhaka, Bangladesh.

El-Adawy, M and K. Khalil. (1998). “An Overview of Health Reform in the MENA Region: The Rationale for Including Reproductive Health Services" . Background paper for Population Challenges in the Middle East and North Africa: Towards the $21^{\text {st }}$ Century, Workshop organised by the Economic Research Forum, Cairo, November 1998.

El-Zanaty, F., E. M. Hussein, G. A. Shawky, A. A. Way, and S. Kishor. (1996). Egypt Demographic and Health Survey (EDHS) 1995. Calverton, Maryland [USA]: National Population Council [Egypt] and Macro International Inc.

Elias, C. (1996). “A Puzzle of Will: Responding to Reproductive Tract Infections in the Context of Family Planning Programs". Social Change. September-December 1996: Vol. 26 No. 3-4.

Fathalla, M.F. (1991). "Reproductive Health: A Global Overview". Annals of New York Academy of Sciences. Vol. 1, P. 1-10.

Fortney, J.A. (1995). "Reproductive Morbidity: A Conceptual Framework". Family Health International - Working Papers. Sept. No. WP95-02.

Hardee, K. and K. Yount. (1995). From Rhetoric to Reality: Delivering Reproductive Health Promises Through Integrated Services. Family Health International Working Papers. 
Hardee, K., K. Agarwal, N. Luke, E. Wilson, M. Pendzich, M. Farrell and H. Cross. (1999). "Reproductive health policies in Eight Countries: Progress Since Cairo". International Family Planning Perspectives, Vol. 25, Supplement, p. S2-S9.

Hussain, M.A., G.S. Rahman, N.G. Banik, N. Begum. (1996). "A Study on Prevalence of RTI/STDs in a Rural Area of Bangladesh", Save the Children (USA). Dhaka

Khan, M., S. R. Rao, R.B. Gupta, B. Patel, L. Caleb, J. Tuladhar and J. Townsend. (1998). "Integrating RTI services in primary health care system: observations from an operations research in Uttar Pradesh, India". Improving Reproductive Health: International Shared Experience (Proceeding of a two-day International Workshop in Bogor, West Java, December 4-5, 1997). Jakarta: The Population Council. p. 169-186.

Khattab, H., K. Khalil and N. Younis. (1996). " Socio-medical Dimensions of Women's Utilization of Reproductive Health Services in Giza, Egypt". Proceedings of the Arab Regional Population Conference in Cairo, December 8-12, Vol. 3. Liege: International Union for the Scientific Study of Population, p. 101-122.

Khattab, H., M. Geneidy and N. Karraz Shorbagi. (1999). Health Education as a Component of Health Promotion. Intervention Study Policy Paper.

Khattab, H., O. Kamal, A.M. Farag and N. Abou-Seoud. (2000). Nurses Outreach Manual for Primary Health Care. Reproductive Health Intervention Study Manuals. Cairo, 2000.

Mamdani, M. (1999). "Management of Reproductive Tract Infections in Women: Lessons From the field". In Saroj Pachauri and Sangeeta Subramanian (eds.) Implementing a Reproductive Health Agenda in India: The Beginning. New York: The Population Council, p. 435-505.

Tsui, A. et al., eds., Reproductive Health in Developing Countries: Expanding Dimensions, Building Solutions (Washington, DC: National Academy Press, 1997). 
Pachauri, S. (1995). Defining a Reproductive Health Package for India: A Proposed Framework. Regional Working Papers, No. 4, The Population Council.

Wasserheit, J. (1989). "The Significance and Scope of Reproductive Tract infections Among Third World Women". International Journal of Obstetrics and Gynecology. Supplement 3 (1989): 145-68.

Younis, N., Khattab, H., Zurayk, H., El-Mouelhy, M., Fadel Amin, M., and Farag, A.M. (1993). "A Community Study of Gynecological and Related Morbidities in Rural Egypt" Studies in Family Planning, Vol. 24, no. 3 , pp. $175-186$. 



\section{APPENDIX I: The Medical Record}

Health center:

Serial number:

Date of first visit:

Name:

Address

No. of deliveries

Rhesus factor (RH):

Age:

No. of abortions:

No. of live births:

Type of previous deliveries (O.H.): $\quad$ Normal $\square \quad$ Assisted $\square \quad$ Cesarean section $\square$

Obstetric history (Past history):

\section{$\underline{\text { Antenatal Care }}$}

Date of last menstrual period:

Expected date of delivery:

\begin{tabular}{|l|c|c|c|c|c|c|c|c|c|c|c|c|}
\hline Date & $\begin{array}{c}\text { Comp- } \\
\text { laint }\end{array}$ & BP & $\begin{array}{c}\text { Wei- } \\
\text { ght }\end{array}$ & $\begin{array}{c}\text { Oedema } \\
\text { of lower } \\
\text { limbs }\end{array}$ & $\begin{array}{c}\text { Fundus } \\
\text { level }\end{array}$ & $\begin{array}{c}\text { Fetal } \\
\text { pulse }\end{array}$ & $\begin{array}{c}\text { Fetal } \\
\text { Posi- } \\
\text { tion }\end{array}$ & $\begin{array}{c}\text { Hemo- } \\
\text { globin }\end{array}$ & $\begin{array}{c}\text { Urine } \\
\text { analy } \\
\text {-sis }\end{array}$ & $\begin{array}{c}\text { Blood } \\
\text { sugar }\end{array}$ & $\begin{array}{c}\text { Refer- } \\
\text { ral }\end{array}$ & $\begin{array}{c}\text { Comme } \\
\text { nts/ } \\
\text { treat- } \\
\text { ment }\end{array}$ \\
\hline & & & & & & & & & & & & \\
\hline & & & & & & & & & & & & \\
\hline & & & & & & & & & & & & \\
\hline & & & & & & & & & & & & \\
\hline & & & & & & & & & & & & \\
\hline & & & & & & & & & & & & \\
\hline
\end{tabular}

Comments on referral :

Date of referral:

Evaluation of current pregnancy:

Post-Partum follow-up

Date of Delivery:

Type of delivery:

Place of delivery:

Attendant:

\begin{tabular}{|l|l|l|l|l|l|l|l|l|l|}
\hline Date & Complaint & $\begin{array}{c}\text { Fundus } \\
\text { level }\end{array}$ & $\begin{array}{c}\text { Temperatur } \\
\mathrm{e}\end{array}$ & BP & $\begin{array}{c}\text { Status } \\
\text { of } \\
\text { infant }\end{array}$ & Breast & $\begin{array}{c}\text { Breast- } \\
\text { feeding }\end{array}$ & Tests & $\begin{array}{c}\text { Com- } \\
\text { ments }\end{array}$ \\
\hline & & & & & & & & & \\
\hline & & & & & & & & & \\
\hline & & & & & & & & & \\
\hline & & & & & & & & & \\
\hline & & & & & & & & & \\
\hline
\end{tabular}




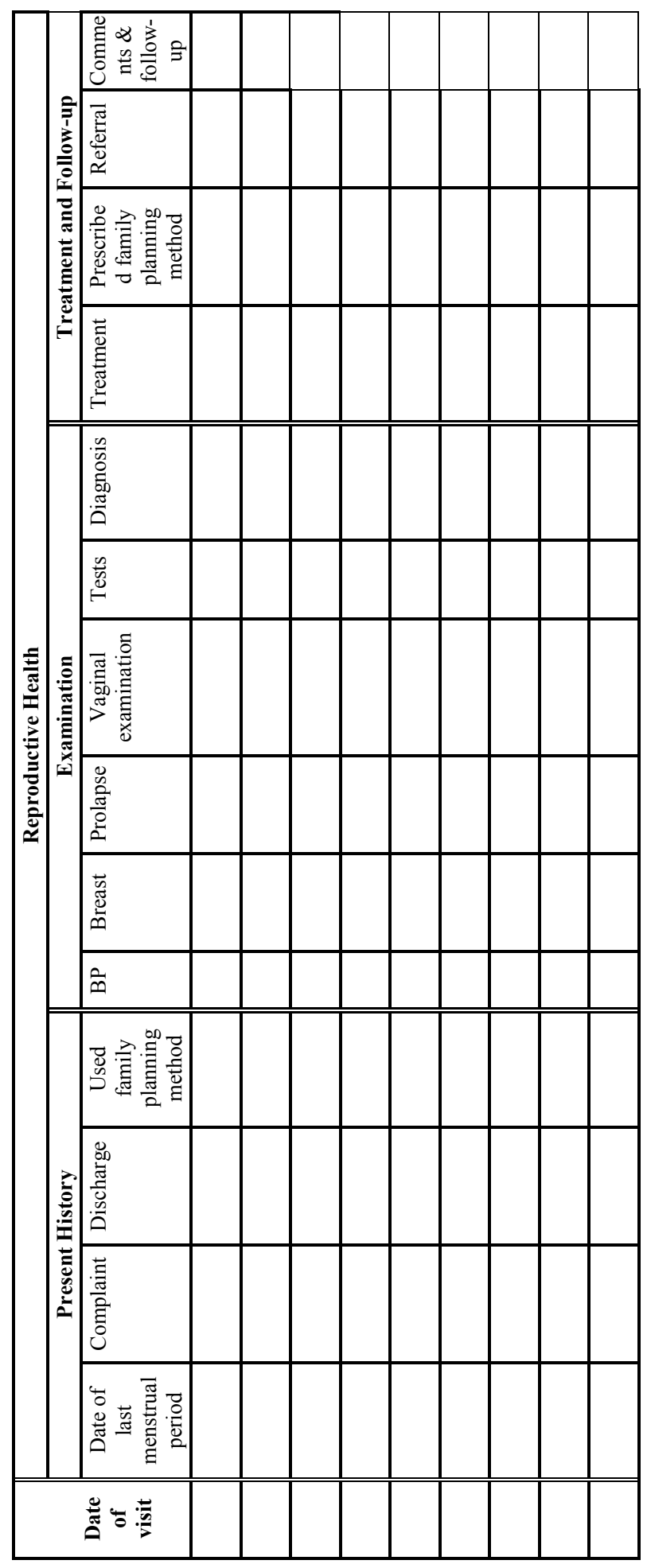




\section{Policy Series in Reproductive Health}

No. 1• Huda Zurayk, Nabil Younis, Hind Khattab

Rethinking Family Planning Policy in Light of Reproductive Health

Research, 1994 (in Arabic 1995)

No. 2 - Nabil Younis, Karima Khalil, Huda Zurayk, Hind Khattab

Learning about the Gynecological Health of Women, 1994 (in Arabic 1995)

No. 3• Hind Khattab, Huda Zurayk, Nabil Younis, Olfia Kamal

Field Methodology for Entry into the Community, 1994 (in Arabic 1995)

No. 4 Hind Abou-Seoud Khattab, Huda Zurayk, Olfia Ibrahim Kamal, Francoise Ghorayeb, Nadine Karraze Chorbagi An Interview-Questionnaire on Reproductive Morbidity: The Experience of the Giza Morbidity Study, 1997

No. 5• Raeda Al-Qutob, Salah Mawajdeh, Laila Nawar, Salama Saidi, Firas Raad Assessing the Quality of Reproductive Health Services, 1998

No. 6• Karima Khalil, Abdel Moneim Farag, Assem Anwar, Dina Galal, Olfia Kamal, Nadine Karraze Shorbagi, Miral Breebaart, Hind Khattab, Nabil Younis and Huda Zurayk Integrating an RH Framework within Primary Care Services: The Experience of the RH Intervention Study, 2000

\section{Monographs in Reproductive Health}

No. 1• Hind Khattab

Women's Perception of Sexuality in Rural Giza, 1996

No. 2• Hania Sholkamy

Women's Health Perceptions: A Necessary Approach to an Understanding of Health and Well-Being, 1996

No. 3• Farha Ghannam

The Social Construction of the Female Body in Low-Income Cairo, 1997 
